\title{
Engineering for animals
}

\section{Biomechanics explores natural solutions to the physical problems of living.}

\author{
Comparative Biomechanics: Life's \\ Physical World \\ by Steven Vogel \\ Princeton University Press: 2003. 582 pp.

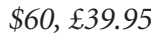

\section{Daniel E. Lieberman}

Biology and engineering have a complex, often discordant, relationship. Living systems are intrinsically messy, so most biologists spend a lot of time analysing untidy subjects such as variation, ecological interactions and the multitudes of tangled, genetic, developmental and metabolic pathways that organisms use. In biology, noise is often a kind of signal, and generalizable principles are hard to find. By contrast, engineers can take a more reductionist approach to the world, deducing and testing the inherent principles and mechanisms by which things fail, work or can be made to work.

Despite these differences, the two fields are vitally important to one another. The physical world poses many basic challenges, such as gravity, viscosity and pressure gradients, to all living creatures, which in turn have evolved an astonishing array of solutions. Many of these, such as paddles, valves and hydrostats, are so widespread that we rarely notice them. Others perform so well that we marvel at their superiority to human-made devices. Did you know that fleas can accelerate at 2,000 $\mathrm{m} \mathrm{s}^{-2}$ - that's 20 times greater than the space shuttle during launch? That silk has a tensile strength similar to that of steel? Or that oak trees can generate pressures of 500,000 Pa through evaporation? Nature is a pretty impressive engineer.

Biomechanics, the intellectually vibrant intersection of engineering and biology, is fundamental to our efforts to study everything from how proteins fold to how whales float. More biologists ought to study engineering and vice versa. But the challenges of integrating these fields can be daunting, particularly for students with a phobia about maths, unhappy memories of physics classes, or simply the lack of an inspiring teacher. There are a handful of wonderful books on biomechanics (many by R. McNeill Alexander), as well as more focused books on human, vertebrate or plant biomechanics, but no general textbooks. Now, thanks to Steven Vogel's Comparative Biomechanics, we have a delightful and comprehensive textbook that is perfect for undergraduates and those of us who need a refresher.

Vogel concentrates on three tasks. First, he reviews the basic principles of physics and biology that underlie biomechanics, such

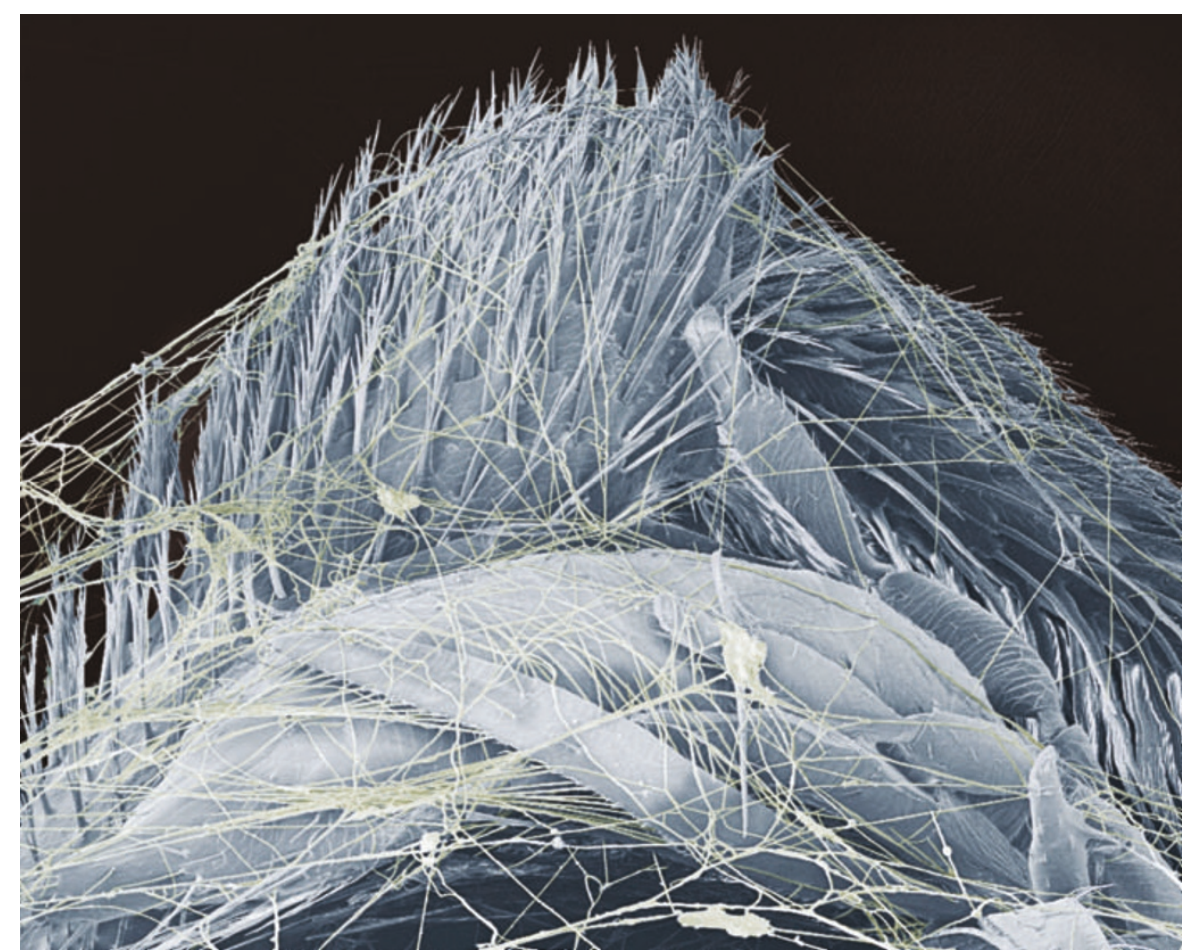

It's a wrap: the flexibility and strength of spider silk spells the end for captured insects.

as units, forces, quantities and questions of scale. Second, he reviews everything that an organism would ever want to know about fluids, focusing mostly on the ways in which plants and animals cope with the physical properties of air and water. Here we encounter everything from solubility and surface tension to the all-important Reynolds number (the ratio of inertial forces to viscous forces). And third, he reviews the material and structural properties of the solid substances from which we are made. Of particular interest are the ways that plants and animals generate and resist forces in order to move or stay where they are.

Throughout the book, Vogel introduces the formulae and principles that matter in a clear manner, and illustrates them with a dizzying array of biological and physical examples. For instance, we learn how prairie dogs construct their burrows so that they are ventilated using the Bernoulli principle (as the speed of a gas or liquid increases, its pressure decreases); how basilisk lizards are able to run on water (and why a human would have to weigh just $4.6 \mathrm{~g}$ to accomplish the same feat with our feet); how the penis inflates without losing girth (the trick is to avoid helical fibres); and why you should never drink champagne from a plastic cup (you'll lose more bubbles).

As these examples suggest, this book is tremendous fun to read. Vogel writes with an effervescent sense of delight in his subject. The text is laced with wit and humour, and sprinkled with eclectic examples of nature's many marvels. None of the fun, however, diminishes the clarity.

In Vogel's world, plants and animals receive equal treatment in the context of the physical problems they encounter. In that sense, the comparative method he uses is based on problems of physics, not evolutionary relationships: tubes are treated as tubes, regardless of what kind of organism they serve. Regrettably, this perspective leaves little room to explore key problems in evolution. Vogel mentions only in passing various debates on topics such as constraints, adaptation and the mechanisms by which organisms can or cannot alter in response to changes in their environment. Of particular note, he sidesteps the issue of optimization and the extent to which natural selection drives organisms towards supposedly better ways to overcome the challenges posed by their particular environments.

I hope that Vogel will inspire a new generation of college-level classes on biomechanics. For many, this book will become a standard reference text, the sort of thumbworn classic whose location on your shelf you instinctively know.

Daniel E. Lieberman is professor of biological anthropology, Harvard University, 11 Divinity Avenue, Cambridge, Massachusetts 02138, USA. 